\title{
oren \\ Influence of Volitional Competencies on Achievement Goals of People with Physical Disability in Physical Activity Settings
}

Authors' contribution:

A) conception and design of the study

B) acquisition of data

C) analysis and interpretation of data

D) manuscript preparation

E) obtaining funding

\section{Ioannis Proios}

Aristotle University, Thessaloniki, Greece

ABSTRACT

This study's purpose was to investigate any possible relationship between the goal perspectives (task and ego orientation) and volitional competences (persistence, expedience, and purposefulness) in physical activities settings. Participants were 134 people with a physical disability (103 men and 31 women) with age ranging from 14 to 67 years. All participants participated in physical activities. Participants filled out the Measure Athletes' Volition - Short (MAV-S), and Task and Ego Orientation in Sports Questionnaire (TEOSQ). Results revealed that volitional competencies are predictors goal perspectives in physical activity settings. In addition, the findings showed that the expedience is a stronger predictor to task orientation, while persistence competence is to ego orientation. In conclusion, the present study is considered to offer new knowledge on the achievement goal orientation people with physical disabilities in physical activity contexts. The first one is that volitional competencies (expedience and purposefulness) are significantly positive predictors of task orientation. The second conclusion is that persistence competence is significantly positive predictor, while purposefulness competence is negative predictor of ego orientation.

KEYWORDS volition, achievement goals, physical disability, physical activities

\section{Introduction}

Achievement goal theory (AGT) is a widespread theoretical perspective for studying motivation and was used quite intensively in the past three decades in physical activity settings (Bortoli, Bertollo, \& Robazza, 2009; Roberts, Treasure, \& Conroy, 2007; Smith, Smoll, \& Cumming, 2009). Pintrich (2000) argued that achievement goals represent an integrated and systematic approach to the study of human motivation in achievement settings because they encompass not just the reasons for engaging in an achievement task but also the standards or criteria for judging successful performance.

Achievement goal theory assumes that the individual central motive for participating in achievement contexts is to develop or demonstrate ability (e.g., Ames, 1992; Dweck, 1986; Nicholls, 1989). Nicholls (1984) argued that more than one conception of ability exists, and that achievement goals and behavior may differ depending on the conception of ability held by the person. The perception of ability demonstration differs among people and the environment and happens according to two-goal orientations (task and ego) (Nicholls, 1989). Task 
orientation for achievement goal illustrates the trend of someone's perception of ability and success using selfreferenced criteria. The person high in task orientation feels most successful when he or she has exerted high levels of effort and observed mastery of a skill. While, ego orientation illustrates the trend of perception of ability and success compared to others (White, 1998). The ego-oriented individual judges the feelings of competence and adequacy by employing normative or other-referenced criteria.

According to motivation theories, motives are considered to be sufficient to explain the individual's complete behavior. However, there are views that argue that motives are not enough, as interpretive constructs, to explain the entire act. Appleton, Christenson, Kim, and Reschly (2006) reports that "One can be motivated but not actively engage in a task. Motivation is thus necessary, but not sufficient for engagement." Motivation is the "antecedent cause," while persistence as a form of behavioral engagement is the "publicly observable behavior" (Reeve, 2012). Kuhl (1987) argues that motivation leads only to the decision to act. Acts in sports are considered as urged (e.g., achievement goals), nevertheless the actions urged by motive is not necessary to be fulfilled (Kuhl, 1983, 1985, 1987), in order to be fulfilled, the intervention of volition is needed. He strongly advocated that a distinction be made between motivational and volitional issues in research. Heckhausen (2007) reports that motivation and volition weighing and wanting are contrasting mindsets that serve distinct functions.

Kuhl (1985) defines volition as a mediating factor that "energizes the maintenance and enactment of intended actions" (Kuhl, 1985, p. 90) and therefore goes beyond motivation. Sechenov maintained that "volition is a psychic phenomenon that directs goal-oriented behavior, particularly in adverse conditions" (Ryba, Stambulova, \& Wrisberg, 2009, p. 276). According to Ryba et al. (2009), the assessment of volition as a psychic phenomenon enables a better understanding of the structure of personality volitional manifestations, with each manifestation comprising intellectual (cognitive), affective (motivational) and operational components (skills).

Ach $(1905,1910)$ was the first psychologist who raised the concept of volition. He supported that motivation and volition are two different aspects of the will. Modern views argue that the theoretical constructs of motivation and volition refer to two related yet very distinct states of motivation (Achtziger \& Gollwitzer, 2007; Heckhausen, 1991). Kuhl (1983) reported that two forms of motivation are existing "selection motivation" and "realization motivation". The first addresses the motivational process of making a decision for a particular goal and against alternative goals. The second involves the volitional processes of maintaining and enhancing the commitment to a goal that one has decided for so that it can be put into action.

Recently, Proios and Proios (2016) based on the viewpoint that volition is a psychic phenomenon that directs goal-oriented behavior, particularly in adverse conditions, developed the instrument Measurement Athletes' Volition - Short (MAV-S) for the estimation of the strength of the volitional competencies of the participants in athletic activities (competitive and recreational). The items of MAV-S contained constructs relevant to the elements of volition such are a continuous effort, effort with difficulties, decision making, persistence in the effort, intention and goal that explain the three volitional competencies (persistence, expedience, and purposefulness). Persistence is a personal skill describing the efforts undertaken by the individual to achieve a goal, for example in sports. Purposefulness is a construct suggesting that an individual's action serves a purpose or is intentional. Expedience represents another personal skill and characterizes individuals who do not hesitate to make decisions and implement them.

In the literature the relationship goal orientations and volition were tested using linear regressions and as indicators of the goal orientations (e.g., Agbuda \& Xiang, 2008; Elliot, 1999; Gao, Podlog, \& Harrison, 2012; Guan, 2004; Guan, Xiang, McBride, Keating, 2013). This demonstrates the lack of knowledge about the predictive ability of volition to goal orientations. Furthermore, for the control of the relationship between goal orientations and volition, simple correlations were used (e.g., Proios \& Proios, 2016; Sideridis \& Kaplan, 2011). Concerning the correlation analysis, it is a statistical measure that describes the size and direction of a relationship between two or more variables. However, a correlation between variables does not automatically 
mean that the change in one variable is the cause of the change in the values of the other variable. In all, also, the above researches results supported the view that goal orientations are related to volition.

To date, in assessing volition, usually volitional intentions or general expressions of volition were used but there is no concrete element of volition (e.g., Chatzisarantis, Frederick, Biddle, Hagger, \& Smith, 2007; Di Paula \& Campbell, 2002; Elbe, Szymanski, \& Beckman, 2005; Kuhl \& Fuhamann, 1998; Lufi \& Cohen, 1987; Novak, 2014; Proios \& Proios, 2016; Sideridis \& Kaplan, 2011). In some cases, persistence act as one single construct (e.g., Kottinen, Toskala, Laakso, \& Konttinen, 2006) and the persistence together with the effort as one single construct were used (e.g., Agbuda \& Xiang, 2008; Fincham, Hokoda, \& Sanders, 1989; Gao, Podlog, \& Harrison, 2012; Guan, Xiang, McBride, Keating, 2013; Xiang \& Lee, 2002), although persistence and effort represent two different constructs theoretically. The use of three elements of volition demonstrates the importance of the present study. The control, also, the effect of the volition in achieving goal orientation emphasises the importance of this study. The purpose of the present study is to investigate any possible relationship between the goal perspectives and volitional competencies in physical activities settings. The main hypothesis in the present study is the existence of a relationship between the task and ego orientation and volitional competencies.

\section{Method}

\section{Participants}

The participants in this study were 134 people with physical disability ( $n=103$ men, and $n=31$ women) without mental retardation. Their age ranging from 14 to 67 years $(\mathrm{M}=34.98, \mathrm{SD}=10.59)$. All participants participated in physical activities (competitive and recreational).

\section{Procedure}

Prior to the beginning of the research, ethical approval and relevant permissions were asked from the participants. For individuals that participated in competitive sport activities in public sports organizations, special requests for permission were made for their participation to relevant authorities. Same process was followed for individuals who have not participated in sport activities, asking the relevant permission from the managers of rehabilitation centers. Following, the researchers informed the participants of the content of the questions featured in the questionnaires, as well as of the purpose of the present study.

\section{Measures}

Achievement goal: A validated Greek version (Papaioannou \& McDonald, 1993) of the Task and Ego Orientation in Sports Questionnaire (TEOSQ; Duda \& Nicholls, 1992) was used in order to assess dispositional goal orientations. The stem was "I feel most successful in my sport when..." TEOSQ is a questionnaire consisting of 13-items. It includes two independent subscales measuring task (seven items; e.g., I learn new skills) and ego (six items; e.g., I come first) orientations as regards participation in sports. TEOSQ has demonstrated adequate internal consistency with satisfactory alpha coefficients for both the task $(\alpha=.79)$ and ego $(\alpha=.81)$ subscales (Duda \& Whitehead, 1998). In the present study, the alpha coefficients were .88 and .86 for task and ego, respectively.

Volition: The Measure Athletes' Volition - Short (MAV-S; Proios \& Proios, 2016) was used to assess the volition of participants. In this scale participants through 15 items describe the range of intensity participants put in some operations in order to achieve their goals in sport and physical activities settings on a Likert scale ranging from 1 (strongly disagree) to 7 (strongly agree). The MAV-S consists of three subscales that measure competencies as persistence (5-item; e.g., I insist in exercising even though conditions are not good), expedience 
(6-item; e.g., I feel capable of executing anything I am asked to do) and purposefulness (4-item; e.g., I exercise intensively because I feel satisfaction). The scale has demonstrated acceptable internal consistency for the persistence $(\alpha=.74)$, expediency $(\alpha=.70)$, and purposefulness $(\alpha=.78)$. In the present study, the alpha coefficients were $.81, .85$ and .87 for persistence, expediency and purposefulness, respectively.

\section{Data analysis}

Descriptive statistics were obtained, and preliminary data analyses were conducted to estimate the responses of athletes on psychological constructs in sport settings. Simple correlations were calculated to test the relationships between variables. Finally, a hierarchical multiple regression was conducted in order to investigate the influence of volitional competences (predictors) in a sequential way, within a criterion (task and ego orientations) (Cohen, 2001; Wampold \& Freund, 1987). All analyses were completed using SPSS for windows version 22.0.

\section{Results}

\section{Descriptive statistics and correlations}

Table 1 provides means and standard deviations for all the investigated variables. Regarding the goal orientations, on average, participants exhibited higher scores in the task orientation and lower in ego orientation. They also exhibited high scores in volitional competence expedience, and low in competence persistence.

Table1. Descriptive Statistics, Cronbach $\alpha$ and Correlations for all variables

\begin{tabular}{llllllll}
\hline Variables & $\boldsymbol{M}$ & $\boldsymbol{S D}$ & $\boldsymbol{A}$ & $\mathbf{1}$ & $\mathbf{2}$ & $\mathbf{3}$ & $\mathbf{4}$ \\
\hline 1.Task & 3.99 & .61 & .88 & - & - & - & - \\
2.Ego & 2.61 & .81 & .86 & $.32^{* *}$ & - & - & - \\
3.Persistence & 5.01 & 1.24 & .81 & $.63^{* *}$ & $.32^{* *}$ & - & - \\
4.Purposefulness & 5.66 & 1.20 & .87 & $.69^{* *}$ & .12 & $.77^{* *}$ & - \\
5.Expedience & 5.70 & 1.00 & .85 & $.73^{* *}$ & $.19^{*}$ & $.82^{* *}$ & $.84^{* *}$ \\
\hline
\end{tabular}

Note: Statistical significant $* \mathrm{p}<.05 ; * * \mathrm{p}<.01$

Source: own study.

Correlations amongst the measures are shown in Table 1. The results indicated that the task orientation had a high positive correlation with the three volitional competencies (persistence, purposefulness and expedience). On the contrary, the ego orientation had a low positive correlation only with volitional competencies persistence and expedience.

\section{Relationship between volitional qualities and goal orientations}

Two hierarchical multiple regression analyses with method stepwise (Table 2) were performed to test the ability of volitional competencies of participants in the present study, to forecast the formation of goal orientations in physical activities settings. The correlations amongst predictor and dependent variables were investigated and are presented in Table 1. All predictor variables were statistically correlated with goal orientations, except purposefulness competence with the ego orientation, which indicates that the data was suitably correlated with the dependent variables for examination through linear regression to be undertaken. The correlation between the predictor variables (persistence, purposefulness, and expedience), and the dependent variables (task and ego orientations) were all modest to large, ranging from $\mathrm{r}=19, \mathrm{p}<.05$ to $\mathrm{r}=.73, \mathrm{p}<.01$. 
First hierarchical multiple regression: in the first step one predictor was entered: expedience. This model was statistically significant $F(1,132)=1504.61, p<.001$ and explained $53 \%$ of variance in task orientation. After entry of purposefulness quality at Step 2 the total variance explained by the model as a whole was $55 \%$ ( $\mathrm{F}(2$, $131)=80.74, \mathrm{p}<.001)$. The introduction of purposefulness competence explained additional $2 \%$ variance in task orientation, after controlling for expedience, and purposefulness $\left(\mathrm{R}^{2}\right.$ Change $=.02, \mathrm{~F}(1,131)=5.61, \mathrm{p}<$ .05). In this analysis, more a step was used entered as predictor the persistence competence. The output showed that there is no significant increase in prediction of task orientation by addition of persistence to the equation. Thus, based on were reported models two predictor variables are statistically significant for task orientation with expedience recording a higher Beta value $(\beta=.51, \mathrm{p}<.001)$ than the purposefulness $(\beta=.26, \mathrm{p}<.05)$.

Table 2. Hierarchical Multiple Regression

\begin{tabular}{|c|c|c|c|c|c|c|c|}
\hline Variable & $R$ & $R^{2}$ & $\begin{array}{l}R^{2} \\
\text { Change }\end{array}$ & $\boldsymbol{B}$ & $S E$ & $\boldsymbol{\beta}$ & $t$ \\
\hline \multicolumn{8}{|l|}{ Task } \\
\hline Step 1 & .73 & $.53 * *$ & $.53 * *$ & & & & \\
\hline Expedience & & & & .45 & .04 & $.73 * *$ & 12.27 \\
\hline Step 2 & .74 & $.55^{*}$ & $.02 *$ & & & & \\
\hline Expedience & & & & .31 & .07 & $.51 * *$ & 4.69 \\
\hline Purposefulness & & & & .13 & .06 & $.26^{*}$ & 2.37 \\
\hline \multicolumn{8}{|l|}{ Ego } \\
\hline Step 1 & .31 & $.10 * *$ & $.10 * *$ & & & & \\
\hline Persistence & & & & .21 & .05 & $.31 * *$ & 3.80 \\
\hline Step 2 & .37 & $.13^{*}$ & $.04 *$ & & & & \\
\hline Persistence & & & & .36 & .08 & $.54 * *$ & 4.24 \\
\hline Purposefulness & & & & -.20 & .09 & $-.30 *$ & -2.32 \\
\hline
\end{tabular}

Note: Statistical significant $* \mathrm{p}<.05, \mathrm{p}<.01$

Source: own study.

Second hierarchical multiple regression: in the first step one predictor was entered: persistence. This model was statistically significant $\mathrm{F}(1,132)=14.45, \mathrm{p}<.001$ and explained $9.9 \%$ of variance in ego orientation. After entry of purposefulness competence at Step 2 the total variance explained by the model as a whole was $13.4 \%$ $(\mathrm{F}(2,131)=10.14, \mathrm{p}<.001)$. The introduction of purposefulness competence explained additional 3.5\% variance in ego orientation, after controlling for persistence, and purposefulness $\left(\mathrm{R}^{2}\right.$ Change $=.035, \mathrm{~F}(2,131)$ $=5.36, \mathrm{p}<.05)$. In this analysis, more a step was used entered as predictor the expedience competence. The output showed that there is no significant increase in prediction of task orientation by addition of persistence to the equation. Thus, based on were reported models two predictor variables are statistically significant for task orientation with persistence recording a higher Beta value $(\beta=.54, \mathrm{p}<.001)$ than the purposefulness $(\beta=-.30$, $\mathrm{p}<.05)$.

\section{Discussion}

This study examined the relationship between achievement goals and volitional competencies. Our data revealed significant correlations between achievement goals and volitional competencies. The results were in line with previous findings reported by Proios and Proios (2016) who found that athletes' achievement task orientation was positively related to three volitional competencies (persistence, expedience, and purposefulness), while ego orientation only with competence expedience. Based on this finding we can assume that intentions to achievement goals, in the sport contexts, are experienced on average as volitional. This way is due to beliefs that sports of people with physical disabilities are a self-motivation act. This finding, also, provides additional support that achievement goals do not function in isolation from one another and volition should be included in 
research on motivation and achievement. Only in this way we can fully understand athletes' cognition, affect, and behavior in athletic settings.

From the regression analysis the finding is the contribution that volitional competences made to the prediction of achievement goals. Specifically, the regression analysis showed that volitional competences expedience and purposefulness predicted task orientation on achievement goal in athletic settings, but persistence did not. That is, athletes' competence of persistence failed to emerge as a significant predictor of self-reported task orientation. The competence (expedience) of individuals to make decisions and activate them (e.g., decision making and persistence in the effort), but also the competence (purposefulness) of an individual acting within a purpose or intent, seem to improve the usefulness of task orientation in achievement goals in physical activities. The contribution of volitional competencies expedience and purposefulness to the prediction of task orientation is additionally in agreement with the view that has supported that participation in decision-making contributes to personal growth by enhancing their feelings of self-worth and self-confidence and by facilitating the development of their problem-solving skills (Williams, 2001). In addition, the recent finding can be explained with planned behavior theory which claims that the intentions reveal the individual's behavioral performance in sport settings (Ajzen, 1985). Furthermore, the above result of the present study is supported from findings from other studies which found that mastery-oriented individuals tend to attribute success to effort, cooperation, and intrinsic interest (Solomon \& Boone, 1993; Walling \& Duda, 1995), and that mastery goal orientation is related to a variety of adaptive achievement behaviors, such as exerting consistent effort, persistence in the face of setbacks, and improved performance (Ames, 1992; Duda, 2005; Dweck, 1999).

The result of the present study states that persistence competence does not contribute to the prediction of task orientation which can be explained with the tenets of the self-efficacy theory (Bandura, 1986). According to this theory persistence is a skill affected by expectations of self-efficacy (Bandura, 1977; Bandura, Adams, \& Beyer, 1977; Bandura \& Schunk, 1981). This view is reinforced by the report that persistence is malleable and may be altered by task-related and personal-motivational determinations (Dweck \& Leggett, 1988; Sideridis \& Kaplan, 2011). This existence of possible differentiation of persistence competence can explain the above finding since the competence differentiation from effort is not linked to task orientation (Nicholls, 1989).

Another research finding from the regression analysis is, also, the contribution of volitional competences persistence and purposefulness to the prediction of ego orientation in physical activity settings. The competence of persistence in a person expressed through " continuous effort " and "effort with difficulties" seems to positively influence the usefulness of ego orientation in achievement goal in physical activities. The contribution of volitional competence persistence to the prediction of ego orientation is additionally in agreement with a number of theories that have emphasized the relationship volition and goals (Bandura, 1986). As already referred previously, persistence is a competence influenced by expectations of self-efficacy, an event that can lead to the association of persistence with ego orientation because this orientation is linked to the differentiation of concept of competence where the competence differs from effort (Nicholls, 1989). According to the social cognitive theory of motivation namely of the self-determination theory which suggests that humans have a set of needs that should be satisfied in the social context. One of these is the individual's needs to feel autonomous in performing an activity. According to Deci and Ryan (2000), autonomy involves being volitional in such a way as to represent one's integrated sense of self. Calvo, Cervello, Jimenez, Iglesias, and Murcia (2010) maintained the relation between autonomy and sport persistence. Finding from other studies suggested that athletes' ego-oriented show a positive relation to tension-pressure (Gutierrez, 2011).

Contrary to persistence, for the competence of purposefulness of the findings, in the present study, showed a significantly negative predictor of ego orientation. This finding can be explained by the fact that when an individual's ego is involved it leads to negative achievement behaviors, especially in the case when questions about the adequacy of one's ability exist (White \& Duda, 1993), as for example people with a physical disability. Findings from other studies showed that ego orientation has been linked, for example, with decreased intrinsic 
motivation for sport involvement (Smith, Smoll, \& Cumming, 2009). This finding reveals a possible diminished existence of purpose or intention to achievement goal in athletic settings a situation which is contrary to the competence of the purposefulness characterized by the elements of the intention and goal settings (Proios \& Proios, 2016).

The result of the present study that expedience competence does not contribute to the prediction of ego orientation can be explained from the view that performance-avoidance goals (ego orientation) are negatively related or unrelated to effort (Elliot, McGregor, \& Gable, 1999). This is because athletes with a physical disability who endorse goal orientation are likely to see achievement settings as a threat to their perceived ability and may therefore try to avoid exerting effort and persistence in those settings.

This study is not without limitations. It should be noted that the assessment of constructs volition and goal orientation were based on self-reports. Furthermore, the sample of this study cannot be considered as a representative to allow generalization of the results. Systematic future research is necessary. In conclusion, the present study demonstrated that volitional competencies (persistence, expedience, and purposefulness) were predictors goal perspectives (task and ego orientation) in physical activity settings. In addition, the findings suggest that expedience is stronger predictor to task orientation, while persistence competence to ego orientation.

\section{Conclusions}

In conclusion, the present study is considered to offer new knowledge on the achievement goal orientation people with physical disabilities in physical activity contexts. The first one is that volitional competencies (expedience and purposefulness) are significantly positive predictors of task orientation. The second conclusion is that persistence competence is significantly positive predictor, while purposefulness competence is negative predictor of ego orientation.

\section{Ethics approval and informed consent}

Ethical approval and relevant permissions were ensured. For participants in competitive sport activities from Sport clubs' Directors, Parents and Coaches. For no participants in sport activities from the Managers of rehabilitation centers.

\section{Competing interests}

No potential conflict of interest was reported by the author.

\section{Funding}

This research received no specific funds from any public or private funding agencies.

\section{REFERENCES}

Ach, N. (1905). Ueber die Willenstaetigkeit und das Denken [About volition and thinking]. Goettingen, Germany: Vandenhoeck \& Ruprecht.

Ach, N. (1910). Ueber den Willensakt und das Temperament [About acts of will and temperament]. Leipzig, Germany: Quelle \& Meyer.

Achtziger, A., \& Gollwitzer, P. M. (2007). Motivation and volition in the course of action. In J. Heckhausen \& H. Heckhausen (Eds.), Motivation and action (pp. 202-226). New York: Cambridge University Press. 
Agbuga, B., \& Xiang, P. (2008). Achievement goals and their relations to self-reported persistence/effort in secondary physical education: A trichotomous achievement goal framework. Journal of Teaching in Physical Education, 27, 179191.

Ajzen, I. (1985). From intentions to actions: A theory of planned behavior. In J. Kuhl \& J. Beckman (Eds.), Action control from cognition to behavior (pp. 13-39). Berlin: Springer - Verlag.

Ames, C. (1992). Classrooms: Goals, structures, and student motivation. Journal of Educational Psychology, 84, $261-271$. http://dx.doi.org/10.1037/0022-0663.84.3.261

Appleton, J., Christenson, S., Kim, D., \& Reschly, A. (2006). Measuring cognitive and psychological engagement: Validation of the Student Engagement Instrument. Journal of School Psychology, 44, 427-445. 10.1016/j.jsp.2006.04.002

Bandura, A. (1977). Self-efficacy: Toward a unifying theory of behavioral change. Psychological Review, 84, $191-215$. http://dx.doi.org/10.1037/0033-295X.84.2.191

Bandura, A. (1986). Social foundations of thought and action: A social cognitive theory. Englewood Cliffs, NJ: PrenticeHall.

Bandura, A., Adams, N. E., \& Beyer, J. (1977). Cognitive processes mediating behavioral change. Journal of Personality and Social Psychology, 35, 125-139. http://dx.doi.org/10.1037/0022-3514.35.3.125

Bandura, A., \& Schunk, D. H. (1981). Cultivating competence, self-efficacy, and intrinsic interest through proximal selfmotivation. Journal of Personality and Social Psychology, 41, 586-598. http://dx.doi.org/10.1037/0022-3514.41.3.586

Bourdieu, P. (1978). Sport and social class. Social Science Information, 17(6), 819-840.

Bourdieu, P. (1984). A Social Critique of the Judgement of Taste. Translated by Richard Nice. Cambridge, MA: Harvard University Press.

Bortoli, L., Bertollo, M., \& Robazza, C. (2009). Dispositional goal orientations, motivational climate, and psychobiosocial states in youth sport. Personality and Individual Differences, 47, 18-24. http://dx.doi.org/10.1016/j.paid.2009.01.042

Calvo, T. G., Cervello, E., Jimenez, R., Iglesias, D., \& Murcia, J. A. M. (2010). Using self-determination theory to explain sport persistence and dropout in adolescent athletes. The Spanish Journal of Psychology, 13(2), 677-684. http://dx.doi.org/10.1017/S1138741600002341

Chatzisarantis, N. L., Frederick, C., Biddle, S. J., Hagger, M. S., \& Smith, B. (2007). Influences of volitional and forced intentions on physical activity and effort within the theory of planned behaviour. Journal of Sports Sciences, 25, 699-709. doi:10.1080/02640410600818523

Cohen, D. (2001). Linear transformation used in economics. Washington DC: Federal Reserve Board.

Cury, F., Da Fonséca, D., Rufo, M., Peres, C., \& Sarrazin, P. (2003). The trichotomous model and investment in learning to prepare for a sport test: A mediational analysis. British Journal of Educational Psychology, 73, 529-543. doi:10.1348/000709903322591226

Deci, E. L., \& Ryan, R. M. (2000). The "what" and "why" of goal pursuits: Human needs and the self-determination of behavior. Psychological Inquiry, 11, 227-268. http://dx.doi.org/10.1207/S15327965PLI1104_01

Di Paula, A., \& Campbell, J. D. (2002). Self-esteem and persistence in the face of failure. Journal of Personality and Social Psychology, 83, 711-724.

Duda, J. L. (2005). Motivation in sport: The relevance of competence and achievement goals. In A. J. Elliot \& C. S. Dweck (Eds.), Handbook of competence and motivation (pp. 318-335). New York: Guilford Press.

Duda, J. L., \& Nicholls, J. G. (1992). Dimensions of achievement motivation in schoolwork and sport. Journal of Educational Psychology, 84, 290-299. doi:10.1037/0022-0663.84.3.290

Duda, J. L., \& Whitehead, J. (1998). Measurement of goal perspectives in the physical domain. In J. L. Duda (Ed.), Advances in sport and exercise psychology measurement (pp. 21-48). Morgantown, WV: Fitness Information Technology. Dweck, C. S. (1986). Motivational processes affecting learning. American Psychologist, 41, 1040-1048. doi:10.1037/0003066X.41.10.1040

Dweck, C. S. (1999). Self-theories: Their role in motivation, personality and development. Philadelphia, PA: The Psychology Press.

Dweck, C. S., \& Leggett, E. L. (1988). A social-cognitive approach to motivation and personality. Psychological Review, 95, 256-273.

Elbe, A. M., Szymanski, B., \& Beckmann, J. (2005). The development of volition in young elite athletes. Psychology of Sport and Exercise, 6, 559-569. doi:10.1016/j.psychsport.2004.07.004

Elliot, A. J. (1999). Approach and avoidance motivation and achievement goals. Educational Psychologist, 34, 169-189. https://doi.org/10.1207/s15326985ep3403_3 
Elliot, A. J., McGregor, H. A., \& Gable, S. (1999). Achievement goals, study strategies, and exam performance: A mediational analysis. Journal of Educational Psychology, 91, 549-563. doi:10.1037/0022-0663.91.3.549

Fincham, D. S., Hokoda, A., \& Sanders, F. (1989). Learned helplessness, test anxiety, and academic achievement: A longitudinal analysis. Child Development, 60, 138-145.

Gao, Z., Podlog, L., \& Harrison, L. (2012). College students' goal orientations, situational motivation and effort/persistence in physical activity classes. Journal of Teaching in Physical Education, 31, 246-260. https://doi.org/10.1123/jtpe.31.3.246

Guan, J.M. (2004). Achievement goals among high school students in physical education. Unpublished doctoral dissertation, Texas A\&M University, Texas.

Guan, J., Xiang, P., McBride, R., \& Keating, X. D. (2013). Achievement goals, social goals, and students' reported persistence and efforts in high school athletic settings. Journal of Sport Behavior, 36(2), 149-170.

Gutiérrez, M., Caus, N., \& Ruiz, L.M. (2011). The influence of parents on achievement orientation and motivation for sport of adolescent athletes with and without disabilities. Journal of Leisure Research, 43(3), 355-382.

Heckhausen, H. (1991). Motivation and action. Berlin: Springer.

Heckhausen, J. (2007). The motivation-volition divide and its resolution in action-phase models of behavioral and developmental regulation. Research in Human Development, 4, 163-180. https://doi.org/10.1017/CBO9780511499821

Kottinen, N., Toskala, A., Laakso, L., \& Konttinen, R. (2006). The interaction of goal orientation and perceived competence in predicting sustained participation in competitive sports: A longitudinal study of track and field youth athletes. Participation in Track and Field Sports, 1-18.

Kuhl, J. (1983). Motivation, konflikt und handlungskontrolle [Motivation, conflict and action control]. Berlin: Springer.

Kuhl, J. (1985). Volitional mediators of cognition-behavior consistency: Self-regulatory processes and action versus state orientation. In J. Kuhl \& J. Beckmann (Eds.), Action control: From cognition to behavior (pp. 101-128). Berlin: Springer.

Kuhl, J. (1987). Action control: The maintenance of motivational states. In F. Halisch \& J. Kuhl (Eds.), Motivation, intention, and volition (pp. 279-307). Berlin: Springer.

Kuhl, J., \& Fuhrmann, A. (1998). Decomposing self-regulation and self-control: The volitional components inventory. In J. Heckhausen \& C. Dweck (Eds.), Lifespan perspectives on motivation and control (pp. 15-99). Hillsdale, NJ: Erlbaum.

Lufi, D., \& Cohen, A. (1987). A scale for measuring persistence in children. Journal of Personality Assessment, 51(2), 178-185. doi:10.1207/s15327752jpa5102_2

Nicholls, J.G. (1984). Achievement motivation: Conceptions of ability, subjective experience, task choice, and performance. Psychological Review, 91, 328-346. http://dx.doi.org/10.1037/0033-295X.91.3.328

Nicholls, J. G. (1989). The competitive ethos and democratic education. Cambridge, MA: Harvard University Press.

Novak, E. (2014). Toward a mathematical model of motivation, volition, and performance. Computers \& Education, 74, 73-80.

Papaioannou, A., \& McDonald, A. I. (1993). Goals perspectives and purposes of physical education as perceived by Greek adolescents. Physical Education Review, 16, 41-48.

Pintrich, P. (2000). An achievement goal theory perspective on issues in motivation terminology, theory, and research. Contemporary Educational Psychology, 25, 92-104. doi:10.1006/ceps.1999.1017

Proios, I., \& Proios, M. (2016). Measure Athletes' Volition - Short: Evidences for construct validity and reliability. Journal of Human Performance in Extreme Environments, 12(2), Article 1. doi:10.7771/2327-2937.1072

Reeve, J. (2012). A self-determination perspective theory on student engagement. In S. L. Christenson, A. L. Reschly, \& C. Wylie (Eds.), Handbook of research on student engagement (pp. 149-172). New York: Springer. doi:10.1007/978-14614-2018-7_7

Roberts, G. C., Treasure, D. C., \& Conroy, D. E. (2007). Understanding the dynamics of motivation in sport and physical activity. In G. Tenenbaum \& R. C. Eklund (Eds.), Handbook of sport psychology (3rd ed., pp. 3-30). Hoboken, NJ: Wiley.

Ryba, T. V., Stambulova, N. B., \& Wrisberg, C. A. (2009). Forward to the past: Puni's model of volitional preparation in sport. International Journal of Sport and Exercise Psychology, 7, 275-291. doi:10.1080/1612197X.2009.9671910

Sideridis, G. D., \& Kaplan, A. (2011). Achievement goals and persistence across tasks: The roles of failure and success. The Journal of Experimental Education, 79(4), 429-451.

Smith, R. E., Smoll, F. L., \& Cumming, S. P. (2009). Motivational climate and changes in young athletes' achievement goal orientations. Motivation \& Emotion, 33, 173-183. doi:10.1007/s11031-009-9126-4

Solmon, M. A., \& Boone, J. (1993). The impact of student goal orientation in physical education classes. Research Quarterly for Exercise and Sport, 64, 418-424. doi:10.1080/02701367.1993.10607595 
Xiang, P., \& Lee, A. (2002). Achievement goals, perceived motivational climate, and students' self-reported mastery behaviors. Research Quarterly for Exercise and Sport, 73, 58-65.

Walling, M. D., \& Duda, J. L. (1995). Goals and their associations with beliefs about success in and perceptions of the purposes of physical education. Journal of Teaching in Physical Education, 14, 140-156.

Wampold, B. E., \& Freund, R. D. (1987). Use of multiple regression in counseling psychology research: A flexible dataanalytic strategy. Journal of Counseling Psychology, 34, 372-382.

White, S. A., \& Duda, J. L. (1993). Dimensions of goals and beliefs among adolescent athletes with physical disabilities. Adapted Physical Activity Quarterly, 10(2), 125-136.

White, S. A. (1998). Adolescent goal profiles, perceptions of the parent-initiated motivational climate, and competitive trait anxiety. The Sport Psychologist, 12, 16-28.

Williams, J. M. (2001). Applied sport psychology: Personal growth to peak performance (4th ed.). California: Mayfield.

\section{AUTHOR'S ADDRESS:}

\section{Ioannis Proios}

Iatrou Zanna 17, 54643

Thessaloniki, Greece

E-mail: johnyproios@gmail.com

Received: 27 March 2019; Accepted: 23 October 2019 